\title{
Airborne Hyperspectral Imagery for Agricultural

$$
\text { Businesses in Malaysia }
$$

\author{
Hj. Kamaruzaman Jusoff (Corresponding Author) \\ Yale University \\ Centre for Earth Observation (CEO) \\ Environmental Science Centre \\ 21 Sachem St, New Haven CT 06511, USA
}

Tel: 60-3-8946-7176 E-mail: kamaruz@putra.upm.edu.my

Hj. Malek Hj. Mohd Yusoff, AISP

Universiti Teknologi MARA Perlis

UiTM Arau 02600 Perlis, Malaysia

Tel: 60-4-986-8077 E-mail: malek_uitm@yahoo.com

The research is financed by Aeroscan Precision (M) Sdn Bhd (Sponsoring information)

\begin{abstract}
The Forest Geospatial Information \& Survey Lab in cooperation with Aeroscan Precision (M) Sdn Bhd at Lebuh Silikon, Universiti Putra Malaysia, spent the last four years developing airborne hyperspectral remote sensing and GIS applications, many of which address agriculture, forestry and the environment. This paper wants to make clear from the outset. Despite the lack of significant commercial success for businesses trying to sell airborne hyperspectral remote sensing data and services to agriculture, the only currently available imaging technology being pioneered and developed in UPM, does work. There is no doubt of its benefits to the agriculture industry especially the oil palm plantation giants in saving money, time, increasing yield, enhancing best practices, protecting the environment, and more. Despite that, the company just not made a "real" business of it perhaps due to the market for airborne hyperspectral remote sensing products and services related to agriculture, is still not known to most state and federal departments and agencies on the other. The consumer, for now, is not really in the picture. The commercial side can be broken down into the growers, who produce the food, Farmers Coops that may include growers but also produce food products and food providers. While some states have huge agricultural bases, few have money to invest in airborne hyperspectral remote sensing, which leaves quite a lot of burden on the federal government. The UPM-Aeroscan Precision (M) Sdn Bhd experience launched in 2004, planned to serve the commercial agricultural market by bringing the benefits of airborne hyperspectral remote sensing, also provide a real-time "GIS-ready" made database, and timely crop yield information to the plantation sector and farmer. The vision was simple: the farmer would build his own real-time airborne remote sensing GIS-ready made database documenting fertilizer, watering and planting details in the software (something typically done in a notebook by future high-tech Malaysian graduated farmers) with the use of a crop model to predict the expected yield. The check was to compare that expected outcome to the reality of the airborne hyperspectral remotely sensing images. For that level of detail, the UPM-APSB's AISA very high resolution airborne hyperspectral imagery $(1 \mathrm{~m})$, and in near real-time could only provide the solution for the Malaysian modern generation farmers in the hope that computer technology will reach them. In this paper, what UPM-APSB's AISA airborne hyperspectral remote sensing can bring to agriculture is demonstrated. First off, it can be used to monitor yields, early in the season, and then later. Second, airborne hyperspectral remote sensing can delineate soil zones. A third area of benefit is in field delineation where the boundaries of crops, in support of regulatory procedures could be easily found. The final area is precision agriculture, about best practices, giving a crop just the water, fertilizer, herbicide, etc. it needs to grow to its potential, but no more. The authors feel strongly that precision agriculture could have a significant impact on the Malaysian future environment. If the UPM-APSB's AISA near real-time data can map and provide just enough nitrogen, the impact on the environment is reduced and the plants should still provide their maximum yield. Applying this just enough vision should save the farmer's money on herbicide, water, fertilizer and other such costs.
\end{abstract}


Keywords: Precision agriculture, Remote sensing, Commercial, Oil palm, Sensor

\section{Introduction}

Agriculture is business. It is profitable to those who perceive and practice it as such, and miserable to those who don't. Is that a mere perceptual issue? Malaysians have the perception that agriculture is not a profitable business compared to industrial ventures. This partly explains the poor intakes of students in agricultural programs in universities and of graduates in agric-related jobs. There is some truth to the perception, but a further probe proves the contrary. Facts show that agriculture is indeed big business. The most negotiated topics under the banner of the WTO are agriculture and food. Heading the recent list of Fortune 500 companies in terms of revenue is WalMart, which specializes in retail goods including food and beverages. Other companies involved in consumer goods in the list include Carrefour (France) (ranked $\left.22^{\text {nd }}.\right)$, Metro (Germany) $\left(42^{\text {nd }}.\right)$, Royal Ahold $\left(49^{\text {th }}.\right)$ and Tesco $\left(54^{\text {th }}.\right)$. Eight of the world's largest retail firms are involved in the food business. According to a study by Nielsen (2004), among the top 20 consumer goods that registered the highest growth were soya-based drinks (first), eggs ( $\operatorname{second})$, frozen fruits $\left(6^{\text {th }}.\right)$, salad dressings $\left(7^{\text {th }}\right)$, frozen meat $\left(13^{\text {th }}\right)$ and fresh vegetables $\left(14^{\text {th }}.\right)$. These data show agriculture is a business capable of securing high sales and operating on a global scale. It offers hope and opportunity to local agricultural enterprises. There is no magic in the success of these firms, but the smart strategies of capitalizing on cross-border possibilities and exploiting supply chain management innovations, logistics, computing and biotechnology. Lessons can be learnt from this development. Besides, developing countries as suppliers of raw materials to these companies should be able to secure smart partnerships along the value chain.

Malaysia has its own success stories, with its own global players for primary commodities such as palm oil, rubber and cocoa. The success of these sectors was driven by private estates or agricultural companies that turned the production of these commodities into successful business ventures. The risks and vagaries of agricultural ventures were either internalized or dealt with creatively. Some of the technologies invented were home-grown, such as new planting materials and processing techniques. The success of these private estates is living proof that agriculture can be big business. But the "other" agricultural and food sectors have not been able to match the scale of business of the primary commodity sector. With the current perception that agriculture is a risky and low-return investment, how do we create more "agric-entrepreneurs" or "agribusiness firms"? For sure, entrepreneurs cannot be created overnight. It requires a conducive business environment, education and continuous training, fiscal incentives, credits, technological and infrastructural support, etc. All these strategies have been deliberated in the Government's policy documents. No stone was left unturned. However, agric-entrepreneurs are not entering the economy at the rate expected.

\section{Monitoring agriculture with airborne hyperspectral sensing}

Airborne hypersepctral sensing is the science (and to some extent an art) of acquiring information about the earth's surface without actually being in contact with it. This is done by sensing and recording reflected or emitted energy and processing, analyzing, and applying that information. In remote sensing, information transfer is accomplished by use of electromagnetic radiation (EMR). Electromagnetic radiation is a form of energy that reveals its presence by observable effects it produces when it strikes the matter. It is considered to span the spectrum of wavelengths from $10 \mathrm{~mm}$ to cosmic rays up to $1010 \mathrm{~mm}$, the broadcast wavelengths, which extend from $0.30-15 \mathrm{~mm}$. Figure 1 illustrates an airborne hyperspectral remote sensing process as applied to agricultural monitoring processes where actions can be taken by the farmers at a farm unit level. There are two types of remote sensing, passive e.g. sun radiation, and active e.g. radar. In Malaysia mostly passive remote sensing is used and the Forest Geospatial Information \& Survey Lab (formerly known as Center for Precision Agriculture \& Bioresource Remote Sensing, Institute Bioscience-CPABRS) \& is pioneer of introducing airborne hyperspectral sensing in agriculture. Airborne hyperspectral sensing makes it possible to collect near real-time data on dangerous or inaccessible areas at the desired client or user demand to as high as $0.5 \mathrm{~m}$ spatial resolution (Kamaruzaman, 2007a). Hyperspectral airborne sensors are like having spectrometers in the airspace. They do not obtain images in the same way as you get images from LANDSAT, SPOT or normal optical satellites. Instead what you get is the reflected light in various spectral bands extending beyond the range of the human eye. This combination of spectral bands can for example enable analysis of the different contents of the atmosphere - permitting researchers to correct for atmospheric effects - as well as the mineral contents of soil, bio-chemical constituents like chlorophyll in plants and in water and also biophysical properties such as biomass and leaf area index. There is an opportunity for added information all along the spectral reflectance curve, whereas with conventional images you mostly just interpret what is depicted in the image. Hyperspectral sensors are an improvement on their multispectral counterparts because they use many more spectral bands and so yield more information such as determining the types of leaf fall diseases in rubber plantations (Kamaruzaman and Malek, 2007), and mapping of infrastructures, landuse/cover and rice paddies characteristics (Kamaruzaman, 2006).

(see Figure 1)

Airborne hyperspectral agriculture sensing applications include monitoring deforestation for agriculture conversion, effects of global warming on tropical regions, and agriculture landuse/cover, etc. Airborne hyperspectral sensing also 
replaces costly satellite based sensing and its slow collection on the ground, ensuring in the process that areas or objects are not disturbed (Kamaruzaman, 2007a). When farmers or ranchers observe their fields or pastures to assess their condition without physically touching them, it is remote sensing. Observing the colors of leaves or the overall appearances of plants can determine plant's condition. Remotely sensed images taken from aircraft provide a means to assess field conditions in near real-time without physically touching them from a point of view high above the field. Most remote sensors see the same visible wavelengths of light that are seen by human eye, although in most cases remote sensors can also detect energy from wavelengths that are undetectable to human eye. The remote view of the sensor and it's "ready made GIS" data's ability to store, analyze, and display the sensed data on field maps are what make airborne remote sensing a potentially important tool for agricultural producers (Kamaruzaman, 2007b). Remotely airborne sensed images can be used to identify nutrient, diseases, water deficiency or surplus, weed infestations, insect, wind, herbicide damage, and plant populations. Ranchers use airborne remote sensing to identify prime grazing areas, overgrazed areas or areas of weed infestations. Land institutions use airborne remote sensing data to evaluate the relative values of land by comparing archived images with those of surrounding fields. Airborne remotely sensed images can be used in many applications, for example land use planning and monitoring the condition of forest and agricultural areas. Information from airborne remote sensing can be used as base maps in variable rate applications of fertilizers and pesticides. Information from remotely sensed images allows farmers to treat only affected areas of a field. Problems within a field may be identified remotely before they can be visually identified. Farmers, land care workers and field officers, with their detailed knowledge of the vegetation and soils in their own paddocks or regions, can extract information on productivity from simple displays of the satellite image. Airborne hyperspectral sensing relies on the fact that particular age features of the oil palm landscape such as three, four, 10 or 15 years old, barren areas, and water reflect light differently in different wavelengths that produce a unique spectral signature (Kamaruzaman, 2005a). Grass looks green, for example, because it reflects green light and absorbs other visible wavelengths. This can be seen as a peak in the green band in the reflectance spectrum for green grass above. The spectrum also shows that grass reflects even more strongly in the infrared part of the spectrum. While this can't be detected by human eye, it can be detected by a Near Infrared (NIR) and infrared (IR) sensor. This sensing provides a cost-effective method for mapping and monitoring focused areas, and has the advantage that the spread of diseases such as leaf fall in rubber trees is enhanced by remote monitoring (Kamaruzaman and Malek, 2007).

Archived data can be used to monitor how areas have changed through time. Monitoring information can then be combined with landform information to help predict which areas are at risk from salinity in the future, allowing remedial action to be taken where it is needed the most. This system is also increasingly being used for large-scale environmental monitoring programs. It is able to offer large-scale monitoring relatively cheaply and easily, and can provide a baseline for future monitoring. Remote sensing can provide data on agricultural and forest activities in inaccessible areas, or simply obtain more accurate information than otherwise available. This information can be obtained from airborne hyperspectral images, and interpreted using machine vision techniques to identify different agricultural regions or crop types. The spectral signature from each crop varies according to its characteristics, such as leaf moisture, plant separation and number of leaves per square meter (Kamaruzaman, 2005b).

Airborne hyperspectral sensor systems in aircraft collect image data in various portions of the narrow contiguous electromagnetic (EM) spectrum, and these data contain much information about conditions of agricultural fields. The conditions of interest may include crop health or potential yield, soil conditions, weed infestations, etc. Airborne image data can yield vital information about the variability of these conditions with respect to location, and this kind of information can be used by agricultural producers to optimize their management decisions with respect to location, thus maximizing profit and minimizing environmental effects. Remote sensing offers the possibility of monitoring agricultural resources for rapid and continuous assessment of plant, soil, and water resources (Kamaruzaman, 2004c). This technology has proven a powerful "tool" for assessing the identity, characteristics, and growth potential of most kinds of vegetative matter at several levels (from biomes to individual plants) to bioinformatics (Kamaruzaman, 2004a). Vegetation behavior depends on the nature of the vegetation itself, its interactions with solar radiation and other climate factors, and availability of chemical nutrients and water within the host medium (usually soil, or water in marine environments). A common measure of the status of a given plant, such as a crop used for human consumption, is its potential productivity (one such parameter has units of bushels/acre or tons/hectare, or similar units). Productivity is sensitive to amounts of incoming solar radiation and precipitation (both influence the regional climate), soil chemistry, water retention factors, and plant type.

\section{THE UPM-APSB'S airborne hyperspetral imaging laboratory mission}

The mission of AIRFOR+ is to conduct applied airborne remote sensing research, work with industry and government agencies to develop "real world" precision and site-specific tools for the agriculture and natural resources management. Research conducted by the laboratory ranges from "on-farm" production uses to large-scale agribusiness uses such as regional yield estimations. The laboratory will be staffed with experts in the fields of crop science, agric-forest engineering, extension, agriculture economics, geographic information system and airborne hyperspectral sensing. 
The era of commercial airborne hyperspectral remote sensing for agriculture has finally arrived (Kamaruzaman, 2007a,b). Since the early days of the government run LANDSAT satellite program by The Malaysian Center for Remote Sensing (MACRES), Malaysian remote sensing experts have touted the benefits of remote sensing for crop production management, for eg the use of IKONOS for cabbage market intelligence (Kamaruzaman, 2005). Unfortunately, the technology of these early earth-observing satellites was limited and the sensing system was not validated for agriculture use, perhaps due to the high costs and slow data acquisition issues. Detecting exact locations of potential stresses or nutrient variability within an oil palm plantation field were nearly impossible (Malek et. al., 2007; and Kamaruzaman, 2004b). Quite frequently, the promises of useful applications of remote sensing to commercial agriculture were never kept. To meet these challenges the Forest Geospatial Information \& Survey Lab in Lebuh Silikon is proposing to create the UPM's Laboratory for Airborne Imaging for Tropical Forest and Other Applications (AIRFOR+) as a Faculty of Forestry's Center of Excellence in Universiti Putra Malaysia (UPM), Serdang. The UPM's AIRFOR+ is well positioned to establish itself as a leader in the field of applied airborne hyperspectral agricultural sensing. Many of the components necessary to achieve this goal are resident at UPM and its surrounding community. Many of our nation's top agriculture researchers and extension specialist have appointments with the UPM' specializing in the fields of crop sciences, agricultural engineering, biotechnology, precision farming, and geospatial information systems. Additionally, FGISL/AIRFOR+ is aligning itself with Yale's Tropical Resources Institure and Stanford's Carnegie Airborne Observatory for airborne applications in tropical precision agriculture to collaborate on such projects as calculating and reducing carbon emissions from oil palm plantations, sustainable oil palm management, using dynamic models to monitor agricultural runoff and using data mining and neural network technology to process high spatial and spectral remotely sensed data.

From an industry perspective several major agribusinesses such as FELDA Agricultural Services and TH Group of Plantations have established research plots in Sabah and Riau, Indonesia, respectively. These companies should be viewed as potential industry partners that could benefit from the use of airborne hyperspectral remote sensing technology and would sponsor UPM's research through AIRFOR+. These two oil palm giant companies already have cooperative agreements and contracts with UPM-Aeroscan Precision (M) Sdn Bhd to fund cutting-edge agronomic, geospatial database development technology, and precision agricultural engineering research.

\subsection{The Function of the laboratory}

The focus of AIRFOR + is toward applied research as opposed to basic research. The function of AIRFOR + should be to engage Malaysian agribusinesses in airborne hyperspectral applied remote sensing research, designed to investigate potential business opportunities and to develop new product ideas and application prototypes for Malaysian companies. Emphasis should be placed on working with these businesses to facilitate commercializing the technology by focusing university research capabilities on industry requirements. AIRFOR + can take advantage of the existing relationship between FELDA Agriculture Services and TH Group of Plantations' Commercial Precision Sustainable Oil Palm Management Program. The laboratory should introduce Malaysian companies to spatial information and expose them to the most promising advanced airborne hyperspectral sensing technologies. This will be accomplished by integrating university research activities with industry requirements to take advantage of advanced airborne hyperspectral sensing technologies and applications. Finally the laboratory will expose University students to real-world problem-solving situations through partnership projects with Malaysian or even ASEAN and Asia Pacific rim companies.

\section{Business development and growth opportunities of airborne hyperspectral sensing projects in Malaysia}

Extensive research and development conducted by The Forest Geospatial Information \& Survey Laboratory (FGISL) in collaboration with Aeroscan Precision (M) Sdn Bhd's Project Office based in Lebuh Silikon, UPM, have provided possible breakthroughs in the agricultural, forestry and natural resources fields. A new near- real-time airborne sensing program, UPM-APSB's AISA, will provide its subscribers such as the oil palm giant companies with airborne hyperspectral images and associated information to alert them of their individual oil palm trees and areas that are in possible danger, say pest and diseases or waterlogged, respectively (Figure 2). This early detection could serve as a warning system for crop stress caused by insufficient water, plant disease, insect infestation and other factors. The information retrieved from the airborne sensor has to have its reliability assessed, so that an uncertainty estimate can be considered in any of the models to be developed. This is something that has to be worked on in general - not just for flood models, for instance but agricultural yield forecast models, carbon models, and it is the same across many different EO applications. This geospatial information can save agriculture businesses millions of Malaysian Ringgits (RM) and aid in environmentally responsible decision making.

The goal of the UPM-APSB's AISA program is to develop a company that will utilize communications, airborne sensing and geographic information systems to provide state-of-the-art products and services. UPM-APSB's AISA aims to operate, launch and operationalize an airborne hyperspectral sensor that, unlike its competitors airborne LiDAR, satellite-based IKONOS, QuickBird, and SPOT Image, will provide images covering the entire Malaysia every hour, and relay the information to customers within 24 hours. It currently takes QuickBird or IKONOS a week or two to 
deliver images to its customers, while it takes SPOT three or more weeks. As a near real-time pointable airborne sensor system, UPM-APSB's AISA can provide hourly and/or daily coverage for specific targets upon demand, but it cannot canvas the entire Malaysia in a day, which is one of the major attributes of UPM-APSB's AISA.

\section{(see Figure 2)}

An aircraft prototype has been used in Kemubu Agriculture Development Authority (KADA)'s rice paddies Merdeka estate in Bachok, Kelantan, FELDA Sahabat's oil palm plantations in Lahad Datu, Sabah, and UPM's matured oil palm plantations in Serdang where it has proven to be successful. Several companies, including FELDA Sahabat, KADA and Global Talent Sdn Bhd along with large and medium size individual growers have purchased the geospatial data information (eg. A map of individual counting of oil palms) indicating real usability of the product (Figure 3). Plants meanwhile need water very urgently. They transpire it through their leaves. By using airborne hyperspectral sensing data we can tell the water content and health of plant leaves, based on their spectral characteristics, and on the other hand we can measure soil moisture to help estimate the capacity of the soil to absorb rainfall or whether there will be surface run-off. In 2007, about 50 percent of the money needed for the Oil Palm Sustainable Precision Management Project, for example, will be appropriated by the INNOFUND Research Grant from the Ministry of Science, Technology and Innovation (MOSTI), while the other portion came from Aeroscan Precision (M) Sdn Bhd sources. The FGISL/UPM-APSB/AIRFOR+ is currently looking for partners in agricultural business and information services to begin commercializing and expanding UPM-APSB's AISA in January 2008 fiscal year.

\section{Airborne hyperspectral imaging partnerships and project outcome}

Businesses use remote sensing data to help make decisions. It is therefore important that if you want to make a business out of airborne hyperspectral data you have to keep contact with science and make some new developments - not just relying on the same tools that are available to everyone. For example, a plan is to install a LiDAR in the Cessna 402B aircraft of the Royal Malaysian Air Force (RMAF). This allows us to provide UPM-APSB's customers with low cost hyperspectral data. Bringing the latest airborne hyperspectral sensing techniques from the laboratory to the marketplace is necessary to ensure the business side of airborne hyperspectral sensing in Malaysia. A new algorithm or method for processing (Figure 3)

Airborne hyperspectral sensing observation data with commercial application need to be developed. The airborne hyperspectral remote sensing business must keep up to date with the latest techniques and applications emerging from the scientific and research community. Airborne hyperspectral sensing has a unique and increasing role to play in environmental science, governance and policy making, particularly in respect of deforestation, climate change and carbon stocking. It is already delivering services in areas such as meteorology and agricultural monitoring, and new opportunities are continuously arising as a result of developments in geospatial science and remote sensing technologies. Transforming research-level applications into viable services suitable for use by the wider audience interested in these issues requires practical business know how and is not always a straightforward process. To reflect the diverse needs of both the Earth observation research community and the industrial sector in forming a knowledge transfer partnership is required.

Even though the research is still underway, several products related to the work have already come to market. Aeroscan Precision (M) Sdn Bhd harnessed UPM's geospatial airborne hyperspectral data information to provide innovative geospatial solutions for a variety of industries. It provides tailored solutions for customers' needs and, as a result, has started to make three rather disparate spin-offs: an oil palm crop prescription service for oil palm plantation agencies; an early warning system management tool for oil palm and rice paddies; and an educational service for young Malaysian rice paddies farmers in KADA. Current experimental airborne hyperspectral research produce images in a $1-$ to $2 \mathrm{~m}$ spatial resolution range. With these images one can detect things like roads, bridges, culverst, and small buildings. Within the next few years day-and-night images from UPM-APSB's AISA commercial sensor with sub-meter (0.5 m) resolution or better will be available. At this resolution one can better detect and count individual crop species, buildings and traffic on highways. The service should be available to farmers and those in the agricultural community. FGISL is thinking of commercializing this system through Aeroscan Precision Company providing farmers with automated, digital crop prescriptions within 24 hours of airborne data collection. The service allows customers to generate their own prescriptions and crop scouting maps at any time of the day or night, using Web-based technologies built in collaboration with UPM-Aeroscan that harness over four years of FGISL's precision agriculture algorithms and research. They can print scouting maps showing relative crop health as well as cost reports showing the economics of treating a field with herbicides, insecticides, plant growth regulators, and defoliants. These maps come in electronic formats and as hard copies. Growers can rapidly verify the scouting maps and then download the digital prescription, which is then loaded into an inexpensive Global Positioning System (GPS)-enabled, hand-held computer on the farmer's sprayer equipment. The farmer loads the appropriate fertilizer or crop controller, and then treats the specific area. The ability to focus treatment saves time and money, as manpower and product can be used efficiently. In the case of inorganic pesticides and fertilizers, this approach provides an added environmental benefit, as chemicals with the 
potential of entering groundwater are used sparingly. This represents a jump in commercial applications that many in the business world are not yet aware of.

The UPM-APSB future partnership will probably involve agribusiness. Because agriculture is so important to the Malaysian economy, the second author is currently working with re-known researchers in Yale and Stanford to identify the use of airborne hyperspectral sensing data for precision agriculture and site-specific crop management, especially oil palm, rubber and rice paddies. The commercial firms are not the only ones who benefit from this partnership. The university's role is not to compete with business but to help create more business in areas of rapidly changing technology. This can only be done when we, government, and business are all on the same page.

\section{Application of airborne hyperspectral imaging system technology in agriculture businesses}

Right now in Malaysia there is a big precision agriculture research cum operational program going on in Federal Land Development Authority (FELDA) and probably follow suit with Tabung Haji (TH) Group of Plantations. UPM-APSB is responsible for airborne hyperspectral sensing applications within it, working on one huge test oil palm plantations in Lahad Datu, Sabah. This is a shared cost activity, meaning that $50 \%$ of funding comes from FELDA and $50 \%$ is paid by the company. The authors are participating because it is believe that precision agriculture for sustainable oil palm management will be important in the long-term future for the oil palm industry in Malaysia. The basic idea behind it is to reduce the impact of the oil palm agricultural management on the environment by applying fertilizers, fungicides and pesticides only in the regions it is really needed, on an adaptive basis. This is good for the environment - especially groundwater - and also saves the estate owners money. The accuracy should be sufficient that chemical application can be reduced with no disadvantage for the health of individual plants or the overall yield. The authors are making a strong use of hyperspectral data, UPM-APSB's AISA images for these purposes.

It is important to realize that providing an operational service for customers is different from doing science. The big difference is that the customer just tells us their problem and we have to find a way to solve it. They do not care whether it is with optical or microwave imagery, an airborne sensor or satellite sensor. They just want the final high quality product to provide them the information they need, without wanting to know all the background behind it. Programs like Precision Sustainable Oil Palm Management are very useful for transferring scientific methodologies into practical procedures working on a routine basis. It is important that such procedures get upgraded to provide the best operational information to estate managers and users. It takes good examples and good experiences before a customer feels this really works, airborne hyperspectral data provides relevant information and can be relied on. It can take a long collaboration with a customer before they say this year they want to extend this service from Malaysia to Indonesia or Thailand- it takes time and hard work to gain trust.

\section{The need to develop an airborne hyperspectral agri-business park in UPM's Lebuih Silikon?}

Innovation, dynamic partnerships, accessibility to advanced technologies and facilities: these are some of the critical factors for a sustainable geo-information science agri-business sector to develop. In order to bring these factors together an "Airborne Hyperpectral Agri-Business Park" needs to be established in UPM. This "Airborne Hyperspectral Business Park" constitutes a public private partnership where small and medium sized companies, the national and state government and the National Space Agency ( $A N G K A S A$ in Malay) have to join forces to provide optimal conditions for the Malaysian airborne hyperspectral sensing sector to expand.

Drawing on the experience gained with the execution of MACRES and NSA National Program and building upon traditional Malaysian strengths such as coastal zone management, water management, marine environment and agri-business, the airborne hyperspectral geo-information science sector in Malaysia will start to evolve rapidly. The emphasis of the "Airborne Hyperspectral Business Park" is to boost this growth by exploiting the synergistic effects resulting from clustering the Malaysian geo-information science and airborne hyperspectral imaging industry, one of the largest to be technological research establishments in Malaysia. The participation of several Malaysian Ministries especially Ministry of Science, Technology \& Innovation (MOSTI), Ministry of Agriculture (MOA), Ministry of Defense (MINDEF) and Ministry of Natural Resource \& Environment (MNRE) is of particular importance, because it provides market-driven development of critical technologies and allows for sharing powerful internet connections, airborne hyperspectral sensing Command-and-Control Centers and supercomputing facilities. Another important consideration for clustering this sector in a business park is the ability for end-to-end offering of services, creating new business opportunities in the domestic and international market. By means of a Foundation the "Airborne Hyperspectral Business Park" will be well embedded in the Malaysia's IT knowledge infrastructure with linkages to several other institutions like UPM, MACRES and ANGKASA.

\section{Conclusion}

The business side of hyperspectral data applications and operationalization, especially in the Malaysian sustainable oil palm management is directly related to the accurate and timely determination of individual oil palm problems. Early detection of problems in the field directly affects the cost of treatment as well as oil palm yields in a season. In addition, 
there are enviro-economic implications tied to the targeted use of pesticides, herbicides, and fertilizer in most oil palm plantations. Giant oil palm plantation companies such as FELDA and TH Group of Plantations for instance, will find a great deal of value in the near real-time analysis of UPM-APSB's AISA airborne hyperspectral data, and allow crop management decisions to be made quickly. Oil palm plantation owners will realize greater yields and apply less agricultural chemicals during the growing season. In addition, it is anticipated that agri-business companies and research institutions will make use of the archived spectral libraries developed for oil palm and field analysis. Over time, this data will become more valuable because it will bring to light sustainable oil palm management trends that are currently unknown. The historical airborne hyperspectral data for any plantations will assist estate managers and top management in planning oil palm sustainable production and treatments of problems. Potential users, buyers and sellers of this information may range from the farmer, to the agrochemical producers, to the oil palm companies and industry that collect and analyze these airborne hyperspectral images.

\section{References}

Kamaruzaman Jusoff. \& Malek, Hj. Mohd, Yusoff. (2007). Identification of Leaf Fall Diseases affecting Hevea brasilliensis using a HandHeld Spectroradiometer. Paper Presented at the 2007 Conference on Plantation Commodities "Visionary Agriculture: Malaysian Commodity Crops in 100 Years", 2-4 ${ }^{\text {th }}$. July, 2007. Putra World Trade Center, Kuala Lumpur, Malaysia. 9p.

Kamaruzaman Jusoff. (2004a). From geospatial information technologies to bioinformatics: A Malaysian perspective. Invited plenary paper presented at MSMBB 2004 Scientific Meeting: Advancement of Biotechnology: Consolidating the strength \& resources towards globalization. 19-21 July, 2004. Century Mahkota Hotel, Melaka, Malaysia. 17p.

Kamaruzaman Jusoff. (2004b). Evaluation of spatial variability of soil in an oil palm plantation. Poster Paper presented at the $13^{\text {th }}$ International Soil Conservation Organization (ISCO) Conference, 4-8 July, 2004, Brisbane Convention \& Exhibition center, Queensland, Australia. 4p.

Kamaruzaman Jusoff. (2004c). Pemindahan teknologi maklumat geospatial (TekMaG) kepada komuniti tani: Adakah ia berjaya?" (In Malay). Paper Presented at the 'Seminar Memperkasa Komuniti Tani 2', 25-26 Mei, 2004. Pusat Pendidikan Luar (IDEAL), UPM Serdang, Selangor. Malaysia. 34p.

Kamaruzaman Jusoff. (2005). Market information for cabbage in Cameron Highlands using the IKONOS satellite. Paper accepted for presentation at The International Society For Agricultural Science (ISHS): Improving the performance of supply chains in the transitional economics, July 19-23, 2005. Lotus Pang Suan Kaew, Chiang Mai, Thailand. 7p.

Kamaruzaman Jusoff. (2005a). Airborne hyperpsectral imaging technology for precision oil palm plantation management system (A7). Procs. Agriculture, Biotechnology and Sustainability Conference (Unedited). Technology Breakthroughs and Commercialization-The Way Forward PIPOC 2005. MPOB International Oil Congress, 25-29 September 2005, Sunway Pyramid Convention Center/Sunway Lagoon Resort Hotel, Petaling Jaya, Selangor, Malaysia. Pp. 259-266.

Kamaruzaman Jusoff. (2005b). UPM-Aeroscan's AISA airborne hyperspectral imaging for precision agriculture and forestry. Procs. KUSTEM $4^{\text {th }}$ Annual Seminar 2005 on Sustainability Science and Management: Meeting Challenges in Sustainability Agrotechnology (Sect.8: Sustainable Science \& Technology), 2-5 May, 2005, Primula Beach Resort, Kuala Trengganu, Trengganu, Malaysia. Pp. 869-875.

Kamaruzaman Jusoff. (2006). Precision Management of KADA's Rice Paddies Land Resources in Bachok District, Kelantan Using UPM-APSB's AISA Airborne Hyperspectral Sensor Technology. Abstracts of Papers. Plenary Session. Journal of ISSAAS. Vol. 12, No. 2, December 2006. pp.65-66

Kamaruzaman Jusoff. (2007a). Latest Developments in Research and Applications of Airborne Hyperspectral Imaging. A Public Research Lecture Presentation to The International Institute for Geo-information Science \& Earth Observation, ITC, The Audtorium, $26^{\text {th }}$. January 2007, ITC, Enschede, The Netherlands. 164p.

Kamaruzaman Jusoff. (2007b). Development of Geospatial Database for Sustainable Precision Agriculture with Airborne Hyperspectral Imaging. A Power Point Lecture Presentation to Erasmus Mundus GEM MS Students, Gondwana Room 204, $1^{\text {st }}$. Floor, Geocentrum II, $17^{\text {th }}$. January 2007, Universitet Lund, Sweden. 94p.

Malek Hj. Mohd Yusoff, Kamaruzaman Jusoff and Mohd Hasmadi Ismail. (2007). Soil Nutrient Variability Mapping in UiTM Research Station, Arau, Perlis using Landsat TM7 and Geostatistical Analysis. WSEAS Transactions on Signal Processing. Greece. Issue 1, Vol. 3, January 2007 ISSN 1790-5022:80-87.

Nielson, A. C. (2004). Grocery Shop Directory. ACNielson Checkout Independent Retail News. Top 100 Grocery Brands, March 2004. http://www.acnielson.co.uk/pubs/document/Top 100 brands/pdf 


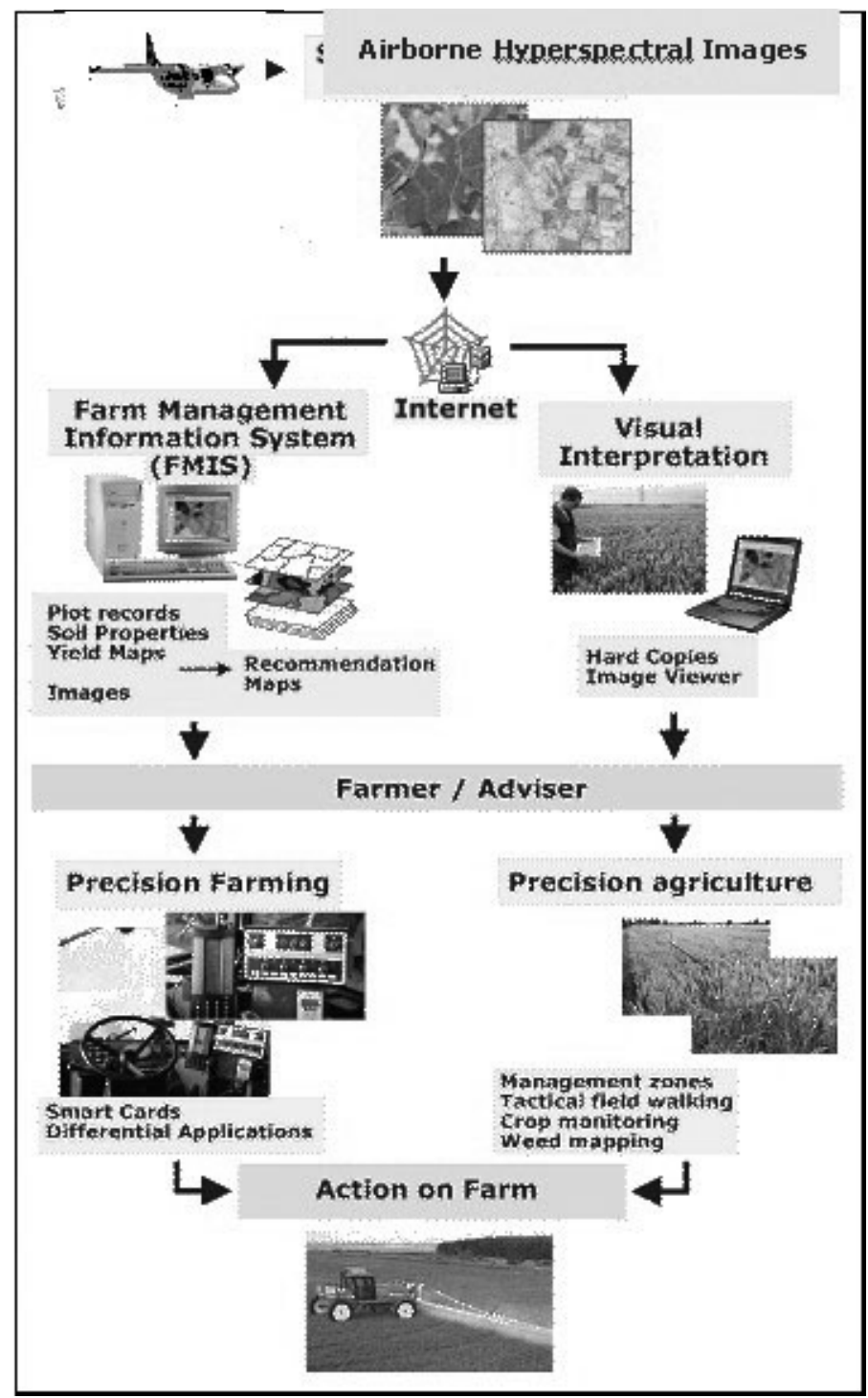

Figure 1. Flow chart of the UPM-APSB's AISA operational and business program 


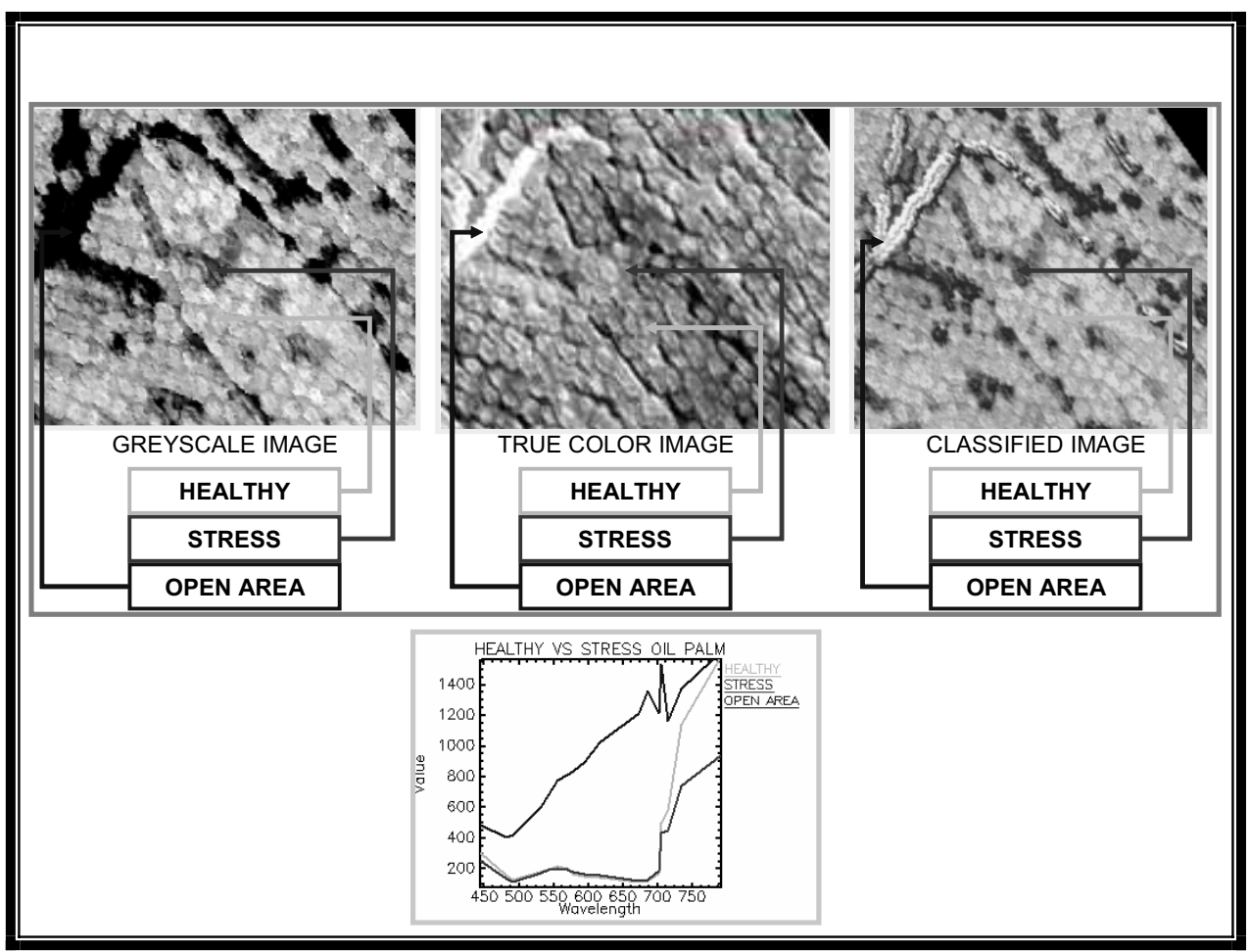

Figure 2. A processed UPM-APSB's AISA airborne hyperspectral image of an oil palm plantation in Sabah, Malaysia showing the healthy, "stressed" palms and open areas

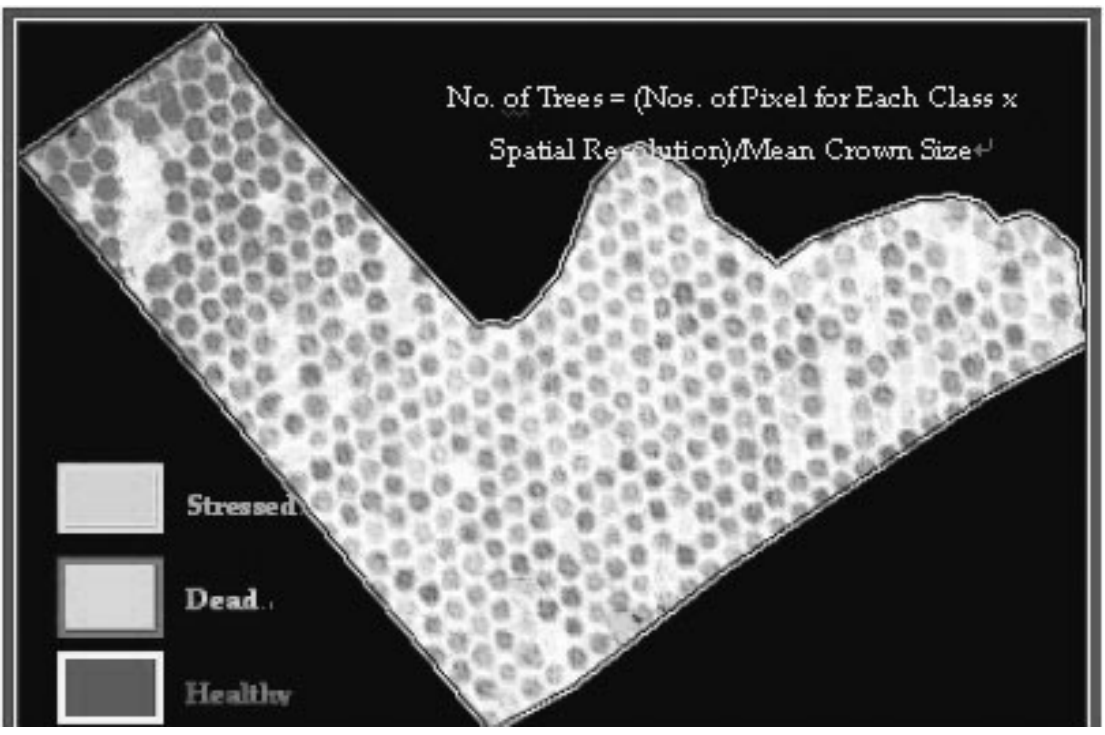

Figure 3. An individual oil palm tree count map showing the healthy (404 trees), "stressed" (199 trees) and dead palms (36 trees) in Pegagau, Sabah 